\title{
Mesocarpo de coco verde utilizado na produção da alface
}

\author{
Use of green coconut mesocarp in the production of lettuce
}

\author{
Alessandro Costa da Silva', Nirany Reis França ${ }^{2}$ \\ 'Professor do Departamento de Química e Biologia da Universidade Estadual do Maranhão - São Luís, MA - Brasil \\ ${ }^{2}$ Estudante de Especialização em Biologia na Universidade Estadual do Maranhão - São Luís, MA - Brasil
}

\section{Resumo}

O objetivo deste trabalho foi avaliar o mesocarpo de coco verde na produção de plantas de alface. Esta pesquisa foi conduzida no Povoado Mojó, no município de Paço de Lumiar, MA. O delineamento experimental foi inteiramente casualizado, com seis tratamentos, quatro repetições, sendo que cada unidade experimental foi constituída de 36 plantas. Todos os tratamentos com mesocarpo de coco verde apresentaram desenvolvimento superior ao da testemunha. Conclui-se, então, que o uso mesocarpo de coco verde com esterco de galinha melhora a qualidade física do solo, aumentando a produção da alface.

Palavras-chave: Alface, Cultivo em solo, Fibra de coco verde

\begin{abstract}
The objective of this work was to evaluate the green coconut mesocarp in production of lettuce. This research was carried out in Mojó village, in Paço de Lumiar County, MA. The experiment was completely randomized, with six treatments and four replications, and each experimental unit was constituted by 36 plants. All treatments with green coconut mesocarp developed better than the control plant. It is concluded that the use of green coconut mesocarp with manure of chicken improve the physical soil quality, increasing the production of lettuce.
\end{abstract}

Key-words: Green coconut fiber, Lettuce, Cultivation in soil 


\section{INTRODUÇÃO}

O coqueiro (Cocos nucifera L.) é uma planta originária da Índia que pertence à família Palmae, uma das mais importantes famílias da classe Monocotyledoneae (GOMES, 2003). O fruto do coqueiro é uma drupa, formada por uma epiderme lisa ou epicarpo, que envolve o mesocarpo espesso e fibroso, ficando mais no interior uma camada muito dura (pétrea), o endossarão. Este fruto fica envolto numa casca externa esverdeada ou amarelada, que com o tempo, torna-se seca e castanha (FERREIRA et al, 1998). Sob a casca do coco, encontra-se uma camada de 3 a $5 \mathrm{~cm}$ de espessura constituída por uma fração de fibras curtas e longas e outra fração denominada pó, que se apresenta agregada às fibras, constituindo o mesocarpo do fruto (ROSA et al., 2001).

A fibra de coco maduro ou seco vem sendo utilizada preferencialmente na indústria. Já a fibra extraída do coco verde (frutos de 7 e 8 meses de idade) é utilizada na forma de vasos como alternativa no uso do xaxim, além de ser indicada para a jardinagem como anti-fungo e substrato para produção de mudas (ARAGÃO et al., 2005). Neste caso, o aproveitamento da casca de coco verde é viável, pois suas fibras e o pó apresentam alta porosidade. Conforme Nunes (2000), o pó de coco é um excelente material orgânico, devido às propriedades de retenção de água, aeração do meio de cultivo e estimulador de enraizamento. A facilidade de produção, baixo custo e alta disponibilidade são outras vantagens adicionais apresentadas por estes materiais (CARRIJO, 2002).

No entanto, poucos estudos têm sido realizados visando à caracterização e utilização da fibra de coco verde (CORRADINI et al., 2009). Algumas pesquisas foram realizadas para verificar a potencialidade do mesocarpo de coco verde, principalmente como substrato para cultivos em recipientes. Não sendo encontrada na literatura o cultivo em solo utilizando o mesocarpo de coco verde, havendo, portanto, necessidade de estudo a este respeito. Segundo Miranda et al., (2004), a utilização da casca de coco verde como cobertura morta apresenta vantagens potenciais, tais como reciclagem de nutrientes, redução das perdas de água por evaporação da superfície do solo e manutenção de níveis de umidade e temperatura, nas camadas superficiais do solo, adequados ao desenvolvimento de raízes e de microrganismos benéficos para as culturas.

Pedra et al., (2006) ressaltam que a casca de coco é um resíduo que apresenta elevada con- centração de tanino, composto tóxico responsável pela redução do crescimento de plantas e outros microrganismos. E segundo Matias et al., (2007), a fibra de coco não lavada além de retardar a germinação proporciona um crescimento menor das mudas, apesar de não significativo estaticamente. Podendo ser provocado pelas altas concentrações de sódio presente na fibra de coco. Isso implica na necessidade da lavagem da fibra de coco antes do seu uso para a retirada de parte do tanino e/ ou outros compostos tóxicos.

A alface (Lactuca sativa L.), pertencente à família Cichoriaceae, é uma hortaliça muito utilizada no nordeste brasileiro, embora seja melhor adaptada a temperaturas baixas do que às altas. A máxima tolerável pela planta fica em torno de $30^{\circ} \mathrm{C}$ e a mínima situa-se em torno de $6^{\circ} \mathrm{C}$, para a maioria das cultivares, exigindo grandes amplitudes térmicas entre o dia e a noite. A umidade relativa mais adequada ao bom desenvolvimento da alface varia de 60 a $80 \%$, mas em determinadas fases de seu ciclo apresenta melhor desempenho com valores inferiores a $60 \%$. Umidade muito elevada favorece a ocorrência de doenças, fato que constitui um dos problemas da cultura produzida em estufa plástica (RADIN et al., 2004).

O objetivo do presente trabalho foi avaliar os efeitos da fibra com o pó de coco verde (mesocarpo triturado), incorporados individualmente ao solo e em mistura com esterco de galinha, na produção de plantas de Lactuca sativa L..

\section{MATERIAIS E MÉTODOS}

O presente trabalho foi realizado em campo experimental localizado no povoado Mojó, no município de Paço de Lumiar - MA, cujas coordenadas geográficas são: latitude $02^{\circ} 30^{\prime} 4.9^{\prime \prime} \mathrm{S}$, e longitude $44^{\circ} 04^{\prime} 22.8^{\prime \prime} \mathrm{W}$, e altitude de aproximadamente $4 \mathrm{~m}$ em relação ao nível do mar. De acordo com Silva (2007), com base na classificação climática proposta por Kooppen, tendo como base a temperatura e a precipitação, o município de São Luís apresenta um clima tropical, do tipo Aw, temperatura anual com média de $28^{\circ} \mathrm{C}$.

Para a caracterização química do solo foram coletas amostras de solo nas profundidades de 0 a $0,20 \mathrm{~m}$, resultante da mistura de amostras simples, sendo que os resultados estão apresentados na Tabela 1 . 
Tabela 1. Resultado da análise química do solo da área experimental. São Luís, Universidade Estadual do Maranhão, 2008.

\begin{tabular}{|c|c|c|c|c|c|c|c|c|}
\hline $\mathrm{pH} \mathrm{em}$ & M.O. & $\bar{P}$ & $\mathrm{~K}$ & $\overline{\mathrm{Ca}}$ & $\overline{\mathrm{Mg}}$ & $\mathrm{H}+\mathrm{Al}$ & $\mathrm{Na}$ & $\overline{\mathrm{Al}}$ \\
\hline$\left(\mathrm{CaCl}_{2}\right)$ & $\mathrm{g} \mathrm{dm}^{-3}$ & \multicolumn{5}{|c|}{$\mathrm{mmol}_{\mathrm{c}} \mathrm{dm}^{-3}$} & & $\mathrm{mg} \mathrm{dm}^{-3}$ \\
\hline 5,4 & 36 & 2 & 0,9 & 19 & 10 & 17 & $\overline{0,5}$ & 4 \\
\hline
\end{tabular}

O resultado da análise de solo indicou ainda que a área do sítio caracteriza-se por apresentar solo classificado como Argissolo vermelho amarelo, textura entre franco e franco-siltosa.

Durante 15 dias antes do plantio das mudas, o solo dos canteiros foi preparado de maneira convencional, com uma aração e uma gradagem, regados e revolvidos duas vezes ao dia para manter a umidade e assim possibilitar o plantio da cultura.

Os cocos (Cocos nucifera L.) utilizados no experimento foram coletados nos pontos de venda de água de coco "in natura" nas praias da cidade de São Luís - MA. Os mesocarpos dos cocos verdes destinados para a preparação dos tratamentos foram obtidos através de uma seqüência das operações de dilaceração, trituração e lavagem para a retirada do excesso de sódio $(\mathrm{Na})$, potássio $(\mathrm{K})$ e tanino, presentes no mesocarpo do coco verde, conforme metodologia descrita por Carrijo (2002).

Os tratamentos apresentaram diferentes quantidades de mesocarpos de coco verde adicionado a mistura de solo mais esterco na proporção de 1:1. Sendo os tratamentos testados: T1 (testemunha $=$ solo); T2 (esterco de galinha + solo); T3 (30 L de mesocarpo de coco verde + solo); T4 (30 L de mesocarpo de coco verde + esterco de galinha + solo); T5 (60 L de mesocarpo de coco verde + esterco de galinha + solo ) e T6 (90 L de mesocarpo de coco verde + esterco de galinha + solo) correspondentes a 1:1; 1:2 e 1:3 do mesocarpo de coco verde em relação ao solo.

Adotou-se o delineamento experimental em blocos inteiramente casualizado, com seis tratamentos e quatro repetições perfazendo o total de vinte e quatro parcelas. As unidades experimentais $(1,80 \mathrm{~m} \times 0,80 \mathrm{~m})$, foram divididas em quatro linhas, cada linha apresentando nove covas, constituído as unidades por trinta e seis plantas espaçadas de $20 \mathrm{~cm} \times 20 \mathrm{~cm}$, com bordadura de $10 \mathrm{~cm}$ nas extremidades da área experimental. Foram consideradas plantas úteis e competitivas as quatorze centrais.

As sementes de alface (Lactuca sativa L.) utilizadas foram do tipo comercial do cultivar/ variedade Rafaela. A germinação foi feita em viveiro construído com solo do próprio local, no qual foi adicionada uma mistura de solo mais esterco de galinha numa proporção de 2:1. Após o plantio, manteve-se uma cobertura até o início da germinação, empregando-se folha de coqueiro, e irrigação em dois períodos do dia até atingirem o tamanho ideal para transplantio. Com 15 dias após a germinação as plântulas foram selecionadas e transplantadas para os canteiros definitivos contendo solo, esterco de galinha e mesocarpo de coco verde.

As características avaliadas foram: a) altura das plantas (medidas realizadas nas mesmas quatro plantas da amostra, através de uma régua, a partir do nível do solo até a extremidade das folhas mais altas); b) área foliar, obtida pelo escaneamento das folhas e conversão das imagens para escala de cinza (8 bits); c) peso das massas frescas e secas da parte aérea, com o emprego de balança digital. Após acondicionadas e identificadas em saco de papel foi feita a secagem se deve em estufa durante $24 \mathrm{~h}$ com circulação de ar à $60-70^{\circ} \mathrm{C}$ até atingir massa constante. Passado este período, o material foi novamente pesado para determinar a massa seca. Os dados foram submetidos à análise de variância pelo sistema estatístico Instat e as médias foram comparadas pelo teste de Tukey $(\mathrm{p} \leq 0,05)$.

\section{RESULTADOS E DISCUSSÃO}

Os resultados obtidos das análises em relação às variáveis altura, área foliar e massa do peso seco das folhas das plantas de alface demonstraram que houve diferenças estatísticas em função dos tratamentos utilizados, ilustrados na Tabela 2.

Os resultados dos diferentes tratamentos demonstraram que os maiores valores de altura obtidos dos tratamentos foram: esterco de galinha + solo (T2), 30L de mesocarpo de coco verde + esterco de galinha + solo (T4) e 90L de mesocarpo de coco verde + esterco de galinha + solo (T6), apresentaram 11,3 cm, 11,6 cm e 11,3 cm, respectivamente, e não diferiram significamente entre si, mas, sim dos tratamentos testemunha $=$ 
Tabela 2: Medidas de altura da planta, área foliar e massa seca da parte aérea em sementes de Lactuca sativa

L. cultivada em solo em função de diferentes proporções de mesocarpo de Cocos nucifera L. com ou sem adubação de esterco de galinha. São Luís (MA), 2008.

\begin{tabular}{|c|c|c|c|}
\hline Tratamentos & Altura (cm) & Área foliar $\left(\mathrm{g} / \mathrm{m}^{2}\right)$ & Massa Seca(g) \\
\hline T1 & $3,3 \mathrm{c}$ & $110 \mathrm{c}$ & $0,6 \mathrm{c}$ \\
\hline T2 & $11,3 \mathrm{a}$ & $332 \mathrm{~b}$ & $1,8 \mathrm{c}$ \\
\hline T3 & $4,6 \mathrm{bc}$ & $758 \mathrm{ab}$ & $5,8 \mathrm{~b}$ \\
\hline T4 & $11,6 \mathrm{a}$ & $701 \mathrm{ab}$ & $6,7 \mathrm{~b}$ \\
\hline T5 & $9,0 \mathrm{~b}$ & $956 \mathrm{a}$ & $9,9 \mathrm{a}$ \\
\hline T6 & $11,3 \mathrm{a}$ & $771 \mathrm{ab}$ & $7,6 \mathrm{ab}$ \\
\hline
\end{tabular}

Médias seguidas da mesma letra, nas colunas, não diferem entre si pelo teste de Tukey $(\mathrm{p} \leq 0,05)$.

$\mathrm{T} 1$ (testemunha = solo); T2 (esterco de galinha + solo); T3 (30L de mesocarpo de coco verde + solo); T4 (30L de mesocarpo de coco verde + esterco de galinha + solo); T5 (60L de mesocarpo de coco verde + esterco de galinha + solo) e T6 (90L de mesocarpo de coco verde + esterco de galinha + solo).

solo (T1), 30L de mesocarpo de coco verde + solo (T3) e 60L de mesocarpo de coco verde + esterco de galinha + solo (T5). Entretanto no tratamento $20 \%$ de mesocarpo de coco verde + esterco de galinha + solo (T5), a média das alturas $(9 \mathrm{~cm})$ não apresentou crescimento satisfatório em 1 (um) dos canteiros, pois as plantas não apresentaram crescimento equivalente às outras plantas do mesmo tratamento, conforme verificado na Tabela 2 .

Com relação à parte aérea, o crescimento das mudas cultivadas por tratamento mostrou valores inferiores no tratamento com esterco de galinha + solo (T2), com valor de $110(\mathrm{~g}) / \mathrm{m}^{2}$. Apresentando diferenças significativas em relação ao tratamento $60 \mathrm{~L}$ de mesocarpo de coco verde + esterco de galinha + solo (T5). Os valores máximos atingidos ao final do experimento foram de 956; $771 ; 758$ e $701(\mathrm{~g}) / \mathrm{m}^{2}$, respectivamente para $60 \mathrm{~L}$ de mesocarpo de coco verde + esterco de galinha + solo (T5), 90L de mesocarpo de coco verde + esterco de galinha + solo (T6), 30L de mesocarpo de coco verde + solo (T3) e 30L de mesocarpo de coco verde + esterco de galinha + solo (T4). Os valores foram similares entre os tratamentos, sem diferenças significativas (Tabela 2).

Para Nogueira et al., (2012) os tratamentos de fibra de coco no desenvolvimento de plântulas de Mimosa caesalpiniifolia Benth determinaram ao maiores valores da área foliar. Segundo Farias et al., (2008) a parte aérea de mudas cultivadas com pó de coco verde desfibrado foi semelhante ao das cultivadas em xaxim, indicando o potencial dessas fibras. Já Yamakami et al., (2006), a fibra de coco também pode ser empregada no cultivo da orquídea Cattlea labiata Lindl. x CattLeya forbesii Lindl. De acordo com Caron et al., (2004), a análise da área foliar da cultura, sobretudo em culturas folhosas, é fundamental para a produção de fitoassimilados e posteriormente distribuição e acúmulo de fitomassa.

Com relação aos parâmetros peso da matéria seca (MS) da parte aérea, observou-se maior peso (g/planta) no tratamento 60L de mesocarpo de coco verde + esterco de galinha + solo (T5), apresentando o melhor desempenho, com valor de 9,9 g. Isso demonstra que as plantas cultivadas na proporção de $20 \%$ de mesocarpo de coco verde apresentaram-se mais hidratadas, o que as torna mais tenras e com melhor aspecto visual. A proporção promoveu resultado estatisticamente superior, dezesseis e meio vezes a biomassa seca da alface em relação à testemunha. Ressaltando que os tratamentos com mesocarpo de coco verde influenciaram a biomassa seca da alface, não diferindo-se estatisticamente entre si. Mas sim, dos tratamentos sem mesocarpo de coco verde, testemunha $=$ solo $(\mathrm{T} 1)$ e esterco de galinha + solo (T2).

Observa-se que, os resultados do desenvolvimento das plantas de alface utilizando mesocarpo de coco verde estão relacionados com o aumento da umidade e aeração do solo. Rosa et al., (2001) observaram que o pó da casca de coco verde apresenta uma grande capacidade de retenção de umidade, sendo capaz de reter água em valor equivalente a praticamente, cinco vezes o seu peso. 
Para Costa (2003) o pó de casca de coco verde é um material com alta porosidade, apresentando boa drenagem e alta capacidade de aeração. Também Oliveira et al., (2006) obteveram melhores resultados na produção de berinjela e pimenta utilizando o pó de coco misturado com composto orgânico e/ou húmus de minhoca.

$\mathrm{Na}$ produção de mudas de pepino Silva et al., (2010) afirmam que as melhores formulações para o adequado desenvolvimento das mudas de pepino incluía a fibra de coco verde. Nos cultivos de plântulas de sabiá a fibra de coco verde promoveu boa emergência e desenvolvimento inicial das plântulas (NOGUEIRA et al., 2012). O mesocarpo de coco verde demonstrou-se eficiente no desenvolvimento de mudas, entretanto para o bom cultivo o mesocarpo de coco verde deve ser lavado. Pois para Oliveira et al., (2008) o pó de coco verde lavado apresentou valores próximos dos substrato comercial, contudo, as plantas cultivadas no material não lavado tiveram uma produção de massa seca visivelmente inferior, deferindo estatisticamente das outras. Silva et al., (2010) mostraram que a produção de mudas de pimentão com a fibra de coco foram superiores aos com substratos comerciais.

Pode-se constatar que neste experimento de cultivo em solo utilizando o mesocarpo de coco verde adicionado ao esterco de galinha proporcionou produtividades significativas com excelente qualidade da alface e, um melhor desenvolvimento das plantas com coloração verde e roseta aberta e atrativas do ponto de vista comercial. E de acordo com Miranda et al., (2011), o uso da fibra de coco possui menor custo e significativa redução no uso de fungicidas e inseticidas.

\section{CONCLUSÕES}

De acordo com os resultados obtidos nas respectivas condições experimentais, podem-se inferir as seguintes considerações:

O mesocarpo do coco verde triturado favoreceu a aeração e retenção de umidade do solo estimulando a altura das plântulas de Lactuca sativa $\mathrm{L}$.

Os tratamentos preparados com mesocarpo do coco verde foram os mais efetivos para aumentar o desenvolvimento da área foliar das plântulas de Lactuca sativa $\mathrm{L}$.

Para uma melhor germinação das plântulas dos tratamentos utilizando o mesocarpo de coco verde deve associá-lo a um aditivo nutricional, como o esterco.

\section{AGRADECIMENTOS}

Ao Conselho Nacional de Desenvolvimento Científico e Tecnológico (CNPq), pelo apoio financeiro à realização deste trabalho.

Ao professor Levy Geralte do Instituto Federal do Maranhão (IFMA) pelo apoio prestado para a realização deste trabalho.

\section{REFERÊNCIAS}

ARAGÃO, W. M.; SANTOS, V. A. J.; ARAGÃO, F. B. Produção de fibra de cultivares de coqueiro. Comunicado Técnico 36. Janeiro, Aracaju - SE. 2005.

ASSIS, A. M., FARIA, R. T.; UNEMOTO, L. K.; COLOMBO, L. A. Cultivo de Oncidium baueri Lindley (Orchidaceae) em substratos a base de coco. Ciências Agrotecnica, Lavras, v. 32, n. 3, p. 981-985, maio/jun., 2008

CARON, B, O.; POMMER, S. F.; SCHMIDT, D.; MANFRON, P. A. Crescimento da alface em diferentes substratos. Revista de Ciências Agroveterinárias, v. 3, n.2, p. 97-104, Lages, 2004.

CARRIJO, O. A. Fibra da casca de coco verde como substrato agrícola. Horticultura Brasileira. v. 20, n. 4, Brasília-DF, 2002.

CORRADINI, E.; ROSA, M. F.; MACEDO, B. P.; PALADIN, P. D.; MATTOSO, L. H. C. Composição química, propriedades mecânicas e térmicas da fibra de frutos de cultivares de coco verde. Revista Brasileira de Fruticultura. v. 31, n. 3, p. 837-846, setembro, Jaboticabal - SP. 2009.

COSTA, A. M. G. Substrato e adubação mineral na formulação de porta-enxerto de gravioleira (Annona muricata) em tubete. 45p. Dissertação (Mestrado) Universidade Federal do Ceará, Fortaleza - CE. 2003.

FERREIRA, J. M. S.; WARWICK, D. R. N.; SIQUEIRA; L. A. A Cultura do coqueiro no Brasil. 2. ed. Brasília: EMBRAPA-SP, 292 p. 1998.

GOMES, Pimentel. Fruticultura Brasileira: Coco. Nobel S/A. São Paulo - SP. 2003.

MATIAS, G. C. S.; COMELI, N. N.; GÓMEZ, G. P.; ROCHA, J. D. S. Avaliação de substratos comerciais para a produção de mudas de alface. Disponí- 
vel: http://www.niltoncometti.com.br. Acesso em 05/01/2012.

MIRANDA, F. R., OLIVEIRA, F. N. S.; ROSA, M. F. Efeito da cobertura morta com a fibra da casca de coco sobre a temperatura do solo. Revista Ciência Agronômica, v. 35, n. 2, p. 335 - 339, jul-dez, 2004.

MIRANDA, F. R.; MESQUITA, A. L. M.; MARTINS, M. V. V.; FERNANDES, C, M. F.; EVAngelista, M. I. P.; SOUSA, A. A. P. Produção de tomate em substrato de fibra de coco. Circular Técnica 33. Fortaleza, CE. Outubro, 2011.

NOGUEIRA, M. W.; RIBEIRO, M. C. C.; FREITAS, R. M. O.; MATUOKA, M. Y.; SOUSA, V. F. L. Emergência e desenvolvimento inicial de plântulas de Mimosa caesalpiniifolia Benth. em função de diferentes substratos. Agro@mbiente On-line.v. 6, n. 1, p. 17-24, jan/abr, Boa Vista, RR. 2012.

NUNES, M. U. C. Produção de mudas de hortaliças com o uso da plasticultura e do pó da casca de coco. Comunicado Técnico 13. Embrapa Tabuleiros Costeiros, Aracaju, 2000.

OLIVEIRA, A. B.; HERNANDEZ, F. F. F.; ASSIS JÚNIOR, R. N. Pó de coco verde, uma alternativa de substrato na produção de mudas de berinjela.

Revista Ciências Agronômica. v. 39, n. 1, p. 39-44, jan-mar. Fortaleza - CE. 2008.

OLIVEIRA, M. K. T.; OLIVEIRA, F. A.; MEDEIROS, J. F.; LIMA, C. J. G. S.; GALVÃO, D. C. Avaliação de substratos orgânicos na produção de mudas de berinjela e pimenta. Revista Verde de Agroecologia e Desenvolvimento Sustentável. v. 1, n. 2, p. 24-32, jul/dez. Mossoró - RN. 2006.

PEDRA, W. N.; MARINO, R. H. Cultivo Axênico de Pleurotus spp. em serragem da casca de coco (Cocos nucifera Linn.) suplementada com farelo de arroz e/ ou trigo. Arq. Insituto. Biogial. v. 73, n. 2, p. 219225, abril/junho. São Paulo - SP, 2006.

RADIN, B.; JÚNIOR, C. R.; MATZENAUER, R.; BERGAMASCHI, H. Crescimento de cultivares de alfaces conduzidas em estufa e a campo. Horticultura. Brasileira. v. 22, n.2, Brasília Apr./ June. 2004.

ROSA, M. F.; SANTOS, F. J. S. S.; MONTENEGRO, A. A. T.; ABREU, F. A. P. A.; COREIA, D.; ARAÚJO, F. B. S.; NORÕES, E. R. V. Caracterização do pó da casca de coco verde usado como subs- trato agrícola. Comunicado Técnico 54. Embrapa Agroindústria Tropical. Fortaleza - CE. 2001.

SILVA, L. G. Utilização Agroecológica de fibra de coco (Coccus nucifera L.) verde para melhoria da produção de alface (Lactuca sativa L.). Dissertação (Mestrado) - Universidade Estadual do Maranhão, São Luís - MA, novembro de 2007.

SILVA, P. S.; ARAUJO, E. S.; SOUZA, R. B.; RESENDE, F. V.; FALEIRO, A. M.; SOUSA, J. M. M. Produção de mudas orgânicas de pepino em substratos a base de fibra de coco verde com aplicação de biofertilizantes. Horticultura Brasileira. v. 28, n. 2, julho. 2010.

SILVA, P. S.; SOUZA, R. B.; TAKAMORI, L. M.; SOUZA, W. S.; SILVA, G. P. P.; SOUSA, J. M. M. Produção de mudas de pimentão em substratos de coco verde fertirrigadas com biofertilizantes em sistema orgânico. Horticultura Brasileira. v. 28, n. 2 , julho. 2010.

YAMAKAMI, J. K.; FARIA, R. T.; ASSIS, A. M.; OLIVEIRA, L. V. R. Cultivo de Cattleya Lindley (Orchidaceae) em substratos alternativos ao xaxim. Acta Scientiarum Agronomy, Maringá, v. 28, n. 4, p. 523-526, 2006. 